\title{
Frail Elderly Adults: Concerns and Recommendations
}

\author{
Shu-Fang Chang ${ }^{1, *}$ \\ ${ }^{1}$ Department of Nursing, College of Nursing, National Taipei University of Nursing and Health Sciences, Taipei, Taiwan \\ ${ }^{*}$ Corresponding author:Shu-Fang Chang, Department of Nursing, College of Nursing, National Taipei University of Nursing and Health Sciences 365 Ming Te Road, Pei-Tou, Taipei, 112, \\ Taiwan, ROC.Tel: 886(2)28227101, Ext.3109, Fax: 886(2)28213233, E-mail: linda@ntunhs.edu.tw.
}

Received: November 30, 2012; Revised: February 21, 2013; Accepted: March 06, 2013

Keywords: Health Care; Frail Elderly

\section{Dear Editor,}

Frailty is a multi-dimensional syndrome; the most common domains assessed include physical function, gait speed or mobility, and cognition $(1,2)$. Most assessment methods allow for subcategories that reflect the degree of frailty, including non-frail, pre-frail, and frail (3-5). As reported previously, the overall prevalence of frailty is around $4.1-14 \%$ in those aged 65 and over in Europe, UK, and USA $(2,6,7)$. Frailty is the precursor of functional degeneration in elderly persons, and is the intermediate stage between independent living and death (8). Numerous studies have indicated that frailty decreases the activity and living quality and causes cognitive function impairment $(3,8,9)$. In addition, it is associated with daily living function disability, falls, and elevated risks of institutionalization or hospitalization, and may even lead to death (10).

Academics have opinions on development factors, clinical definitions, and evaluation methods for frailty and no standardized or consistent concept has been developed. The significance of frailty for the aging in health care is being acknowledged and proponed (2-4). Meanwhile, most assessment methods involve retrospective evaluation that require elderly persons to recall weight variations during the past year or physical activity in the past week $(2,3,10)$. These methods are prone to creating biased memories, and are not feasible for screening high-risk patients. Therefore, the assessment of physical fitness is an objective evaluation tool for determining frailty.

Objective assessments of elderly persons' physical abilities and fitness are highly predictive for frailty and level of disability $(3,11)$. Therefore, objective evaluation of physical fitness status enables early detection for frailty. This enables the further supplementation of relevant guidance and health care interventions to prevent further frailty or mortality.

Consequently, multidisciplinary team including physicians, nursing staff, social workers, psychologists, nutritionist, and rehabilitation therapist should focus on this high-risk population and actively perform research on assessments and intervention programs to prevent or postpone frailty (12)

\section{Acknowledgements}

The author would like to thank Professor Yang R.S. for his suggestions on this manuscription.

\section{Financial Disclosure}

The author reported no conflict of interest.

\section{Funding/Support}

The author would like to thank the NSC 101-2314-B-227001- for funding this manuscript.

\section{References}

1. Sternberg SA, Wershof Schwartz A, Karunananthan S, Bergman $\mathrm{H}$, Mark Clarfield A. The identification of frailty: a systematic literature review.J Am Geriatr Soc. 2011;59(11):2129-38.

2. Wou F, Conroy S. The frailty syndrome. Medicine.(2013);41(1):13-15

3. Fried LP, Tangen CM, Walston J, Newman AB, Hirsch C, Gottdiener J, et al. Frailty in older adults: evidence for a phenotype.J Gerontol A Biol Sci Med Sci. 2001;56(3):M146-56.

4. Ensrud KE, Ewing SK, Cawthon PM, Fink HA, Taylor BC, Cauley JA, et al. A comparison of frailty indexes for the prediction of falls, disability, fractures, and mortality in older men. J Am Geriatr Soc. 2009;57(3):492-8.

5. Xue QL. The frailty syndrome: definition and natural history. Clin Geriatr Med.2011;27(1):1-15.

6. Santos-Eggimann B, Cuenoud P, Spagnoli J, Junod J. Prevalence

Implication for health policy/practice/research/medical education:

Multidisciplinary team works are needed to perform research on assessments and intervention programs to prevent or postpone frailty

Copyright (c) 2013, Kowsar corp. This is an Open Access article distributed under the terms of the Creative Commons Attribution License (http://creativecommons. org/licenses/by/3.0), which permits unrestricted use, distribution, and reproduction in any medium, provided the original work is properly cited. 
of frailty in middle-aged and older community-dwelling Europeans living in 10 countries. J Gerontol A Biol Sci Med Sci. 2009;64(6):675-81.

7. Syddall H, Roberts HC, Evandrou M, Cooper C, Bergman H, Aihie Sayer A. Prevalence and correlates of frailty among communitydwelling older men and women: findings from the Hertfordshire Cohort Study. Age Ageing. 2010;39(2):197-203.

8. Bergman H. Frailty: Searching for a Relevant Clinical and Research. In Paradigm 28th Canadian Geriatrics Society Annual Meeting: Academic Career Day. 2008;11(3):9-11.

9. Abellan van Kan G, Rolland Y, Bergman H, Morley JE, Kritchevsky SB, Vellas B. The I.A.N.A Task Force on frailty assessment of older people in clinical practice. J Nutr Health Aging. 2008;12(1):29-37.

10. Cawthon PM, Marshall LM, Michael Y, Dam TT, Ensrud KE, BarrettConnor E, et al. Frailty in older men:prevalence, progression, and relationship with mortality. J Am Geriatr Soc. 2007;55(8):1216-23.

11. Buatois S, Miljkovic D, Manckoundia P, Gueguen R, Miget P, Vancon $\mathrm{G}$, et al. Five times sit to stand test is a predictor of recurrent falls in healthy community-living subjects aged 65 and older. $J$ Am Geriatr Soc. 2008;56(8):1575-7.

12. Binder EF, Schechtman KB, Ehsani AA, Steger-May K, Brown M, Sinacore DR, et al. Effects of exercise training on frailty in community-dwelling older adults: results of a randomized, controlled trial.J Am Geriatr Soc. 2002;50(12):1921-8. 